\title{
PREDITORES DA INTENÇÃO DE RETORNO ÀS FEIRAS DE NEGÓCIOS: UM ESTUDO COM O PÚBLICO VISITANTE DA VI COSTA VERDE NEGÓCIOS DE ANGRA DOS REIS-RJ
}

\author{
Márcio Moutinho Abdalla \\ Universidade Federal Fluminense - UFF \\ marciomabdalla@yahoo.com.br
}

Recebido em 04/fevereiro/2011

Aprovado em 02/outubro/2012

\section{RESUMO}

O principal objetivo deste trabalho reside em identificar as variáveis que predizem as intenções de retorno, por parte do público visitante, a uma feira de negócios de Angra dos Reis-RJ. A avaliação foi conduzida por meio da realização de uma regressão logística binária, aplicada sobre uma amostra transversal de 277 visitantes do evento. Como resultado, verificou-se que das oito hipóteses testadas apenas três foram aceitas, sendo duas hipóteses relativas ao impacto na predição da intenção de retorno sofrido pela percepção de sacrifício do público visitante, e uma hipótese referente ao efeito da percepção de benefício do evento para a economia local na predição das intenções de retorno. Com tais resultados, conclui-se que o estudo corrobora os pressupostos de Grönroos (2004), ao postular que a maior parcela do valor percebido pelo cliente pode ser remetida à minimização do sacrifício dele, e não propriamente ao aumento dos benefícios ofertados.

Palavras-chave: Intenção de Retorno. Feira de Negócios. Regressão Logística. Sacrifício Percebido. Satisfação.

\section{ABSTRACT}

The main objective of this paper is to identify the variables that predict the intentions of the visitors comeback to a business fair held in Angra dos Reis, Rio de Janeiro. The evaluation was conducted through a binary logistic regression model, applied to a cross-sectional sample composed by 277 visitors. As result, it was found that, of eight hypotheses, only three were accepted. Two of them are associated to the impact of the effort and commitment perception, from the visiting public, in the prediction of the comeback intention, and the third is associated to the effect of the perceived benefits from the event to the local economy, also in the prediction of the comeback intention. Considering these results, one can conclude that the study confirms the assumptions of Grönroos (2004), which postulate that the main factors that contribute to the perceived value are associated to the minimization of the customer effort and commitment, and not only to the increasing of the benefits offered.

Key words: Intent to Return. Business Fair. Logistic Regression. Perceived Sacrifice. Satisfaction. 


\section{INTRODUÇão}

Pride e Ferrell (2001), Churchill e Peter (2005) e Kotler (1998) argumentam que as feiras e as exposições se configuram como importantes elementos promocionais. Para esses autores, o objetivo principal das feiras e exposições é reunir, em um só local, produtores e clientes, por um período curto de tempo, com a finalidade de gerar atenção e conhecimento a respeito de produtos e serviços de uma organização, identificar clientes e gerar vendas. Para Chapman Jr. (1993), as feiras, em alguns segmentos, configuram-se como um dos principais métodos de promoção. Apesar do exposto, verifica-se que os estudos a respeito dessa temática são escassos na literatura de marketing, a qual se limita a definir o que são esses eventos e os supostos benefícios obtidos pelos adotantes de tal prática.

Desde 2004, a região da Costa Verde, litoral Sul Fluminense, composta principalmente pelas cidades de Mangaratiba, Angra dos Reis e Paraty, conta com o evento Costa Verde Negócios, que em 2009 promoveu uma sexta edição. Sediada na cidade de Angra dos ReisRJ, a Costa Verde Negócios, de acordo com Abdalla (2008), caracteriza-se como um dos principais eventos do gênero na região e recebe uma média aproximada de 35 mil visitantes em cada edição.

A importância desse tipo de evento é ressaltada por Britto e Fontes (2002), ao defenderem que, no contexto das inter-relações estratégicas, os eventos se destacam como uma ação concreta e de permanentes resultados obtidos no tocante aos canais de comunicação. Para Konopacki (2005), muito mais que "tirar um pedido”, realizar a venda em uma feira, significa criar uma parceria com o cliente potencial. Para o autor, os expositores, atualmente, são mais eficientes e estão preparados para gastar mais tempo com um visitante, e não apenas distribuir brochuras e coletar cartões de visita. Tanner Jr. e Chonko (1995) mencionam ainda que muitas organizações têm reconhecido o poder das feiras setoriais como um contundente veículo de encurtamento do ciclo de venda, tornando-o mais ágil e mais próximo do público consumidor.

Dessa forma, evidencia-se a necessidade de um maior aprofundamento nos estudos acerca desse fenômeno por vezes citado na literatura de marketing, todavia pouco explorado em profundidade, especialmente no que se refere ao público visitante (ou consumidor). Assim sendo, o presente trabalho pretende identificar, por meio de uma regressão logística binária, as variáveis preditoras da intenção de retorno a uma feira de negócios, por meio de um estudo particularizado ao público visitante da VI Costa Verde Negócios de Angra dos Reis-RJ. Para isso, o trabalho está estruturado em mais quatro seções. No próximo tópico, discutem-se teoricamente os conceitos empregados como suporte na elaboração do modelo estatístico. No terceiro tópico, abordam-se os aspectos metodológicos, onde são detalhados os procedimentos empregados na pesquisa, na coleta e no tratamento dos dados. No quarto tópico, desenvolvem-se as análises descritivas e a análise de regressão logística binária, apresentando o detalhamento dos resultados obtidos. No quinto e último tópico, estabelecem-se as considerações finais e apresentam-se as limitações do trabalho, bem como as proposições de estudos futuros.

\section{Referencial TeÓrico}

\subsection{Feiras e Eventos}

De acordo com Stevens (2005), ao indagar compradores organizacionais sobre resultados tomados na última feira de que participaram, 26\% deles responderam que fecharam compras, 76\% afirmaram que requisitaram uma visita pessoal em sua empresa, $76 \%$ declararam haver solicitado um orçamento e $77 \%$ disseram que encontraram um novo fornecedor. A constatação fortalece a importância da participação de organizações, com fins promocionais, em eventos. Britto e Fontes (2002) definem evento como o somatório de esforços planejados com o fim de alcançar um resultado, definido com base no seu público-alvo. Já o Comitê de Promoção da Associação Brasileira de Anunciantes (2009) conceitua evento como um acontecimento excepcional, com delimitação temporal, gerador de expressivo envolvimento e de mobilização de um grupo ou uma comunidade.

Dentro desse contexto, destacam-se as feiras, conceituadas por Matias (2002) como uma exibição pública, com o objetivo de venda direta ou indireta, composta por diversos estandes, construídos em locais definidos, onde se expõem produtos e serviços para determinado público. Todavia, reforça-se o posicionamento de Konopacki (2005), argumentativo de 
que as feiras extrapolam a função de vendas, funcionando como um verdadeiro elemento fomentador do bom relacionamento cliente-fornecedor.

Para Nassaralla (2006), existem duas caracterizações de feiras, ao se considerar o produto exposto: as feiras verticais (ou setoriais) e as feiras horizontais. Nas verticais, participam apenas empresas com produtos de uma mesma categoria ou grupo de tecnologia, ao passo que nas horizontais os expositores se diversificam e expõem um grande sortimento de produtos e serviços, de diversas categorias. Uma das características das feiras horizontais é a apresentação de lançamentos.

Para Schultz e Robinson (1992), destaca-se, entre os objetivos promocionais das feiras, o incremento das vendas de produtos e serviços entre intermediários, de maneira que esses mediadores promovam os produtos ao consumidor final e favoreçam o aumento da abrangência da distribuição dos produtos e serviços, mediante relacionamento com novos distribuidores e varejistas. Além disso, experimenta-se um encurtamento do ciclo de venda, que ocorre principalmente em virtude do potencial de convencimento gerado pela demonstração dos produtos e serviços (NASSARALLA, 2006).

As feiras possibilitam o desenvolvimento dos elementos relacionais entre fornecedores e compradores em virtude da aproximação e integração das partes, pelos atrativos dos produtos e serviços expostos e pelos materiais promocionais disponibilizados (GOLDBERG; LORIMER, 2001). Dessa maneira, para Nassaralla (2006), a relação de aprendizado entre cliente e fornecedor, especialmente nos mercados business to business (B2B), passa a ser um elemento determinante na geração e na manutenção da vantagem competitiva.

\subsection{Recompra, Retorno e LeAldade}

Lealdade, para Schiffman e Kanuk (2000, p. 158), caracteriza-se como a preferência repetitiva por um produto ou serviço, ou seja, "um consumidor com uma atitude altamente relativa e alto grau de preferência repetido, seria definido como fiel”. A lealdade em relação a um serviço pode surgir de um desempenho tão acima do esperado que encante o cliente. Ela é provável em situações de serviço que envolvam encontros interpessoais extensos. Pesquisas sobre serviços também descobriram que a lealdade pode surgir em função do conforto do consumidor.
O conforto é um estado psicológico em que a ansiedade do consumidor em relação a um serviço foi abrandada e ele se sente tranquilo e calmo, sem preocupações em relação aos encontros de serviços nem tampouco com algum fornecedor específico. Hawkins, Mothersbaugh e Best (2007) e Rust, Zeithaml e Lemon (2001) apontam o desenvolvimento da lealdade, bem como o conhecimento de seus antecedentes, como elemento gerador de grande diferencial competitivo, além de facilitador da geração de bom desempenho organizacional. Para Oliver (1999), a lealdade caracteriza-se por um profundo e seguro compromisso de recompra - no caso deste trabalho, o retorno - e de adesão a um produto ou serviço de forma consistente no futuro, causando, assim, compras repetidas de uma mesma marca ou de um grupo de marcas, apesar das influências situacionais e do esforço de marketing, que têm potencial de causar comportamento de mudança.

Dessa forma, a lealdade a uma marca ou a um evento, de acordo com Amine (1998), requer intensa disposição interna do consumidor em continuar comprando a mesma marca ou visitar o mesmo evento periodicamente. A recompra simples, todavia, parte do pressuposto de que o consumidor busca reduzir os esforços físicos e mentais do processo de compra, adotando apenas um comportamento de manutenção do status quo.

As empresas de serviços podem usar uma diversidade de estratégias básicas para manter e melhorar as relações, entre elas: tratamento justo dispensado aos clientes; oferta de ampliações nos serviços; tratamento dado a cada cliente como se ele (ou ela) fosse particularmente importante. Programas de usuários frequentes são também bastante usados como tática para recompensar a lealdade do cliente e construir uma relação de longa duração (CROCCO; GIOIA, 2005). Segundo Thurau, Gwinner e Gremler (2002), o consumidor deve possuir, além do comportamento de compra repetido, atitude positiva ante os produtos e serviços de uma organização ou a organização em si, para que se considere leal. Dessa maneira, estabelecem-se laços de identidade, fortalecendo a construção do relacionamento organização-cliente. Como o evento em questão apresentou reduzido número de edições, admite-se que não se trate especificamente de lealdade, mas de intenções de recompra ou de retorno, haja vista que as relações estabelecidas, embora duradouras, sofrem com o intervalo de um ano entre as 
edições, o que dificulta o estabelecimento de atitudes como o comprometimento. Mas como os estudos limitados à recompra são escassos, optou-se por adotar alguns princípios da lealdade.

\subsection{SATISFAÇÃo}

Para Mowen e Minor (2008), a lealdade ou mesmo a recompra de uma marca ou de um serviço está intimamente ligada à satisfação do consumidor e ao seu comportamento de reclamação. A lealdade se dá pelo grau em que um consumidor mantém uma atitude positiva em relação à marca, estabelece um compromisso com ela e pretende continuar comprando-a no futuro. Está diretamente influenciada pela satisfação ou insatisfação com a marca, acumulada ao longo do tempo, bem como pelas percepções de qualidade do produto ou serviço que está sendo oferecido.

Somente clientes muito satisfeitos apresentam um alto índice de recompra e uma propensão à comunicação boca a boca positiva. É importante surpreender os clientes de tal maneira que sua percepção da qualidade seja satisfatória o suficiente para reforçar sua lealdade e fazê-los recomprar. (GRÖNROOS, 2004). A satisfação do consumidor é fonte de feedback sobre a qualidade das decisões de marketing de uma organização, influenciando decisivamente a formação da intenção de compra futura do consumidor. Os consumidores satisfeitos costumam fazer comunicação boca a boca sobre uma experiência de compra positiva, afetando diretamente a viabilidade e a lucratividade de uma empresa (FREDERICO; ROBIC, 2006).

Gerar consumidores satisfeitos - e, portanto, vendas futuras - significa fazer com que consumidores continuem a acreditar que a marca ou o serviço atendam suas necessidades e ofereçam valor superior depois que eles os usam (HAWKINS; MOTHERSBAUGH; BEST, 2007).

Para Sheth, Mittal e Newman (2001), os clientes estabelecidos já estão satisfeitos com a empresa. A não ser que exista um forte motivo para fazê-lo, os clientes estabelecidos provavelmente não trocarão seus fornecedores atuais. Se um concorrente deseja conquistar os clientes satisfeitos de uma empresa, deve oferecer um valor significativamente maior, seja na forma de preços mais baixos, seja por meio de um desempenho mais alto.
Os autores afirmam que os custos dos clientes insatisfeitos são assombrosos: 96\% desses clientes não se queixam de atendentes rudes, mas $90 \%$ deles não voltam a comprar do mesmo fornecedor ou contam sua história para pelo menos nove outras pessoas, e 13\% desses ex-clientes insatisfeitos contarão sua experiência para mais de 20 pessoas. A insatisfação, portanto, tem ampla divulgação e desestimula a intenção de recompra ou retorno.

Dessa maneira, propõem-se as seguintes hipóteses: H1 - A opinião favorável em relação ao evento como um todo exerce influência positiva sobre a intenção favorável de retorno.

H2 - A opinião favorável em relação à organização do evento exerce influência positiva sobre a intenção favorável de retorno.

H3 - A opinião favorável em relação aos expositores exerce influência positiva sobre a intenção favorável de retorno.

\subsection{Sacrifício Percebido}

Segundo Grönroos (2004), os clientes ficam satisfeitos com a qualidade percebida desde que o sacrifício envolvido - preços e custos de relacionamento - não seja demasiadamente alto. Clientes satisfeitos podem tornar-se comprometidos com o fornecedor ou prestador de serviços porque confiam na outra parte ou estão contentes com o nível de sacrifício envolvido no relacionamento. Os clientes já existentes podem aumentar seu volume de negócios com o prestador de serviços e novos clientes serão atraídos para a organização, caso os sacrifícios percebidos sejam reduzidos. De acordo com Bolton (1998), alguns grupos de consumidores são mais influenciados pelos sacrifícios que pelos benefícios de uma relação, ou seja, são mais influenciados pelas perdas que pelos ganhos. Dessa forma, Grönroos (2004) argumenta que o valor de uma relação para o cliente por vezes é considerado mais pela redução de sacrifícios do que pela entrega de benefícios incrementados. Seguindo-se a taxonomia de Khalifa (2004), apresentam-se quatro grupos de sacrifícios, a saber: o preço monetário, o esforço envolvido, o tempo despendido e o risco da relação. No estudo em questão, evidenciamse dois grupos de sacrifícios, o tempo e o esforço, que podem inclusive ocorrer simultaneamente:

- o tempo despendido com a participação no evento, 
em função da conveniência dos horários de funcionamento para o público visitante;

- o esforço relativo à acessibilidade do local de realização do evento, ou seja, se o local atende satisfatoriamente (comodamente) o público visitante;

- o esforço relativo ao acesso à infraestrutura do evento como, por exemplo, os banheiros, isto é, e se essa infraestrutura atende satisfatoriamente (comodamente) o público visitante;

Assim, propõem-se as seguintes hipóteses:

H4 - A opinião favorável em relação à infraestrutura do evento exerce influência positiva sobre a intenção favorável de retorno.

H5 - A opinião favorável em relação à adequação do horário do evento exerce influência positiva sobre a intenção favorável de retorno.

H6 - A opinião favorável em relação ao local de realização do evento exerce influência positiva sobre a intenção favorável de retorno.

\subsection{IMAGEM E REPUTAÇÃo}

Para Ayrosa (2002), a imagem é uma compilação de vários conceitos que se agrupam e se complementam, formando um esquema mental sobre ela. Segundo o autor, tais esquemas ou conexões são estruturas cognitivas que representam o conhecimento sobre os estímulos, seus atributos e os relacionamentos entre esses atributos. Segundo De Toni et al. (2008), as imagens constituem um dos materiais intelectuais mais importantes

do homem e são

capazes

influenciar

direcionar

de

0

comportamento

das pessoas. Por

isso, sua plena compreensão se configura como um importante diferencial para um melhor direcionamento das decisões sobre as estratégias de posicionamento de serviços.

De acordo com Oliveira (2007), a imagem possui muitas formas de percepção e classificação, fato que a torna alvo de difícil e subjetivo estudo. Par a autora, duas formas são preponderantemente analisadas na academia: a identidade e a reputação. Na primeira, a percepção é formada pelas características intrínsecas da organização, da instituição, da marca, entre outros fatores, ao passo que, na segunda, a imagem consiste em uma percepção de longo prazo, relacionada com a trajetória da organização ou marca.

Neste trabalho, buscar-se-á, em especial, uma avaliação concernente à reputação. Dessa forma, será dada menor importância às características inerentes à identidade. Para Gioia, Schultz e Corley (2000), o foco na reputação apresenta caráter mais eficaz, em virtude de essa dimensão se caracterizar como um elemento mais estável ao longo do tempo e apresentar maior consistência. Para Hall (1992), a reputação representa o conhecimento e as emoções de um indivíduo sobre uma gama de produtos, que pode ser um fator relevante para atingir vantagem competitiva por meio de diferenciação. Para o autor, a reputação se distingue como o ativo intangível mais importante, difícil de substituir e frágil, que demanda tempo para ser construído.

Dessa forma, propõem-se as seguintes hipóteses:

H7 - A opinião favorável em relação à reputação do evento exerce influência positiva sobre a intenção favorável de retorno.

Quadro 1: Hipóteses e notações 
H8 - A opinião favorável em relação à imagem evento, como elemento fomentador da economia local, exerce influência positiva sobre a intenção favorável de retorno. O Quadro 1 apresenta uma síntese das hipóteses e suas respectivas notações.

\section{Aspectos Metodológicos}

A presente pesquisa caracteriza-se por uma abordagem quantitativa em virtude de obedecer ao paradigma clássico, que postula a existência de uma realidade externa a ser examinada com objetividade, por meio da aplicação de métodos quantitativos (TERENCE; FILHO, 2006). Malhotra (2006, p. 182) classificou esse tipo de pesquisa como descritiva conclusiva, porque “[...] tem como principal objetivo a descrição de algo normalmente características ou funções do mercado”. A abordagem para a obtenção da informação foi realizada por levantamento (survey), definido pelo autor como um tipo de pesquisa que emprega como instrumento de coleta um questionário estruturado, aplicado a uma amostra de uma população, destinado a coletar informações dos entrevistados.

\subsection{Instrumento de Coleta}

Para a execução da pesquisa, valeu-se de um questionário estruturado, autoadministrado, composto por 14 questões fechadas, que objetivou avaliar as opiniões do público frequentador do evento. O instrumento foi concebido com base na fundamentação teórica que originou as hipóteses. Das 14 questões, quatro delas (1, 5, 6 e 7) empregaram escala de medição Likert de cinco pontos, indo de "Discordo totalmente" (1) a "Concordo totalmente” (5). Três questões (2, 3 e 4) foram elaboradas por meio de escala Likert de cinco pontos adaptada, indo de "Totalmente insatisfeito" (1) a "Totalmente satisfeito" (5). Essas oito primeiras questões refletem as hipóteses do modelo, na mesma ordem apresentada no Quadro 1. Para que se tenha uma melhor ideia das questões empregadas no modelo, exemplifica-se aleatoriamente a quinta questão: “O horário do evento está adequado”. O visitante respondeu mediante uma escala de concordância, conforme apontado.

Uma das questões (questão 10) foi concebida por meio de uma escala dicotômica (sim/não) e referia-se à intenção de retorno (ou não) do visitante à feira em uma próxima edição. As demais questões foram compostas por alternativas categóricas, visando à identificação do perfil socioeconômico dos entrevistados.

\subsection{AMOSTRAgEM EMPREgadA}

Para o desenvolvimento desta investigação, aplicaram-se 314 questionários, dos quais 37 foram considerados inválidos por conterem questões não respondidas, ou ainda respostas duplicadas em questões que admitiam somente uma alternativa. A coleta das informações junto ao público visitante foi realizada in loco, por conveniência, sob a forma de um corte transversal (cross-sectional), ou seja, o fenômeno fora avaliado em um restrito período de tempo, mais especificamente, entre os dias 8/10/2009 e 12/10/2009. Empregaram-se, no trabalho de coleta, seis alunos de um curso de administração, devidamente capacitados para o exercício da atividade. Foram considerados respondentes em potencial todos os visitantes com mais de 18 anos. A peculiaridade do objeto de pesquisa norteia a pesquisa a uma amostra por conveniência, em virtude da dificuldade de acesso aos visitantes em momentos posteriores ou mesmo anteriores ao evento. Reconhecem-se, no entanto, as limitações da abordagem empregada, recomendando que sejam evitadas generalizações. Segundo Abdalla (2008), a população média em cada edição do evento é de 35 mil visitantes.

\subsection{Modelo Empregado e Tratamento dos Dados}

Conforme mencionado, o modelo foi desenvolvido pelo próprio autor, com base na literatura corrente. A concepção do modelo também levou em consideração a técnica previamente prevista para o tratamento estatístico dos dados - Regressão Logística Binária -, visando desvelar os elementos preditores da intenção de retorno ao evento.AFigura 1 ilustra a proposta do modelo empregado. 
Figura 1 - Modelo de Regressão Logística Binária

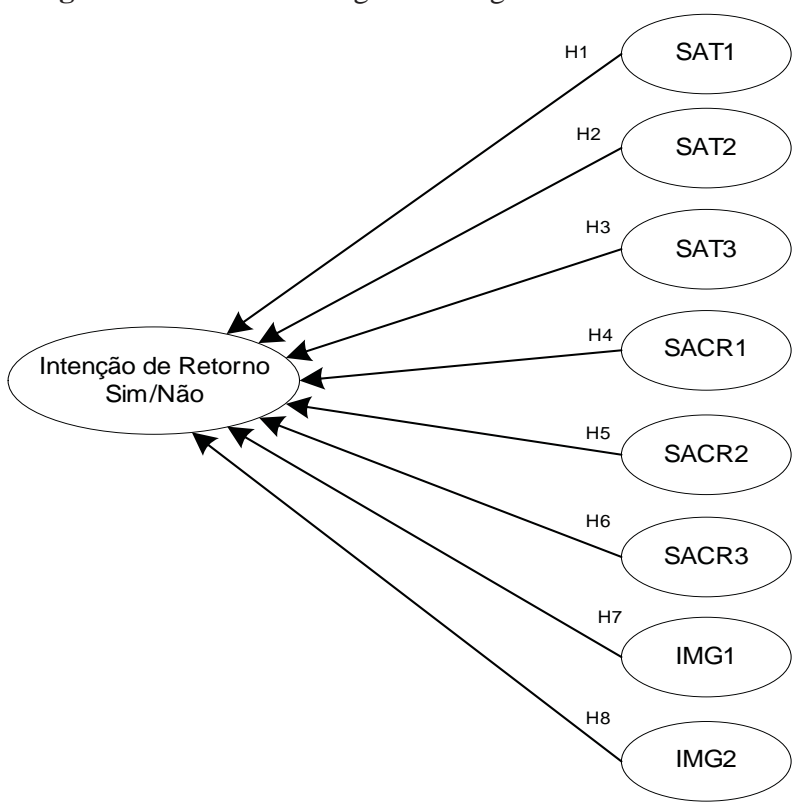

Fonte: Desenvolvido pelo autor.

Os dados foram tabulados e tratados estatisticamente com o auxílio do software SPSS v.15. Para o tratamento multivariado dos dados, empregou-se uma análise de regressão logística binária, que, para Dias Filho e Corrar (2007), explica ou prediz valores de uma variável em função de valores conhecidos de outras variáveis. Esse ferramental estatístico estima a probabilidade de ocorrência de determinado evento ou de um fenômeno que venha a se enquadrar nessa ou naquela categoria. A variável dependente é categórica, assumindo valores binários, e as variáveis independentes são intervalares ou categóricas. Essa é uma das principais particularidades da técnica, em que a variável dependente é dicotômica, ou seja, binária, ou ainda, uma variável dummy - neste caso, a intenção de retorno (intencionado/não intencionado) ao evento. Azevedo (1997) reforça a premissa ao mencionar que a regressão logística é frequentemente usada nos casos em que a variável dependente é binária, isto é, quando aceita apenas dois níveis de respostas como, por exemplo, sim ou não, solvente ou insolvente, doente ou não doente, leal ou não leal, além de outras possibilidades.

Empregou-se o método de análise Forward LR que, de acordo com Pampel (2000), é amplamente utilizado em tratamento de dados com regressão logística. Nesse método, constrói-se a equação de regressão logística, adicionando sequencialmente as variáveis e empregando estimativas de razão de verossimilhança para determinar a variável que será adicionada à equação de regressão.

As variáveis independentes avaliadas no método anteriormente descrito foram: a imagem do evento (IMG1); a satisfação geral com ele (SAT1); a satisfação com a organização dele (SAT2); o sacrifício inerente à infraestrutura (SACR1); o sacrifício inerente ao horário (SACR2); a imagem do evento em relação à contribuição dele para a economia local (IMG2); o sacrifício inerente ao acesso da localização do evento (SACR3); a satisfação do público em relação aos expositores (SAT3). Todas as variáveis foram avaliadas na condição de variáveis independentes em relação à intenção de retorno (LEAL1) ao evento, na condição de variável dependente.

\section{Análise Dos Dados}

\subsection{Análise Descritiva dos dados}

Verificou-se, na análise descritiva, que o evento alcançou um alto nível de aceitação do público visitante. As questões relacionadas à mensuração da satisfação diante dos quesitos estabelecidos invariavelmente apontaram para uma alta satisfação do visitante e uma grande concordância em relação à qualidade percebida do evento. Todavia, é relevante mencionar que, embora o evento apresente uma imagem positiva sob a ótica do visitante, o gasto estimado do público é relativamente baixo. Observou-se que, do público pesquisado, cerca de $59 \%$ gastaram ou gastariam até $\mathrm{R} \$ 200,00$ no evento e $26 \%$ não gastaram ou não gastariam nada. Apenas $5 \%$ dos entrevistados gastaram ou gastariam acima de $\mathrm{R} \$ 500,00$. Contudo, cabe mencionar que esse tipo de evento, muito além de se limitar ao ticket médio, visa ampliar o networking, de modo a fomentar negócios futuros. A faixa etária dos visitantes pesquisados situase predominantemente entre 18 e 65 anos (94\%), ou seja, é composta, em sua quase totalidade, por elementos economicamente ativos. Além disso, 50\% dos entrevistados possuem ensino médio completo, e 30\% nível superior completo. A renda familiar dos participantes (pessoas físicas) variou, em sua maioria, entre $\mathrm{R} \$ 2.001,00$ e $\mathrm{R} \$ 3.500,00$, correspondendo a $26 \%$; entre $\mathrm{R} \$ 1.201$ e $\mathrm{R} \$ 2.000,00$, teve uma representatividade de 20\%; entre $\mathrm{R} \$ 3.501,00$ e $\mathrm{R} \$ 6.500,00$, de $19 \%$. Somente 8\% dos entrevistados apresentaram rendimentos familiares superiores a $\mathrm{R} \$ 6.500,00$, e $10 \%$ do total tinham 
renda familiar abaixo de $\mathrm{R} \$ 700,00$, fato que se atribui à abertura do evento ao público, com entrada franca.

A Tabela 1 apresenta uma síntese da análise descritiva dos dados referentes às questões de 1 a 8 , identificáveis por variáveis contínuas. Observa-se que, sob a ótica do público visitante, todos os quesitos apresentaram alta avaliação, que se confirma pelos valores assimétricos das medidas de tendência central - média e mediana. Ambas as medidas se mantiveram, em todas as variáveis, na proximidade de “4”, revelando grande concordância positiva do público em relação aos quesitos avaliados. A premissa também tem reforço pela baixa dispersão dos dados, confirmados pelos baixos coeficientes de variância e desvio-padrão. Nota-se elevada assimetria das observações em virtude da grande concentração de respostas positivas e da baixa concentração de respostas negativas. O coeficiente de curtose das variáveis analisadas, que, segundo Stevenson (2002), indica até que ponto a curva de frequência de uma distribuição se apresenta mais afilada ou mais achatada do que uma curva normal, apresentou relativa variação

Tabela 1 - Estatísticas Descritivas

\begin{tabular}{|lcccccccc|}
\hline & SAT1 & SAT2 & SAT3 & SACR1 & SACR2 & SACR3 & IMG1 & IMG2 \\
\hline Casos & 277 & 277 & 277 & 277 & 277 & 277 & 277 & 277 \\
Média & 3,860 & 3,970 & 3,990 & 3,750 & 3,900 & 4,060 & 3,960 & 4,110 \\
Mediana & 4,000 & 4,000 & 4,000 & 4,000 & 4,000 & 4,000 & 4,000 & 4,000 \\
Desvio Padrão & 0,854 & 0,910 & 0,821 & 1,154 & 1,073 & 1,090 & 0,904 & 1,012 \\
Variância & 0,730 & 0,829 & 0,674 & 1,331 & 1,152 & 1,188 & 0,818 & 1,024 \\
Assimetria & $-1,340$ & $-1,068$ & $-0,924$ & $-0,750$ & $-0,976$ & $-1,272$ & $-1,054$ & $-1,338$ \\
Curtose & 1,496 & 1,210 & 1,354 & $-0,322$ & 0,130 & 0,933 & 1,496 & 1,493 \\
\hline
\end{tabular}

Fonte: Elaboração própria.

\begin{tabular}{|lllccc|}
\hline & \multirow{2}{*}{ Observação } & \multicolumn{2}{c|}{ PROGNÓSTICO } & INTENCIONADO P \\
& & INTENC (1) & NÃO INTENC. (2) & $\begin{array}{c}\text { Porcentagem } \\
\text { Correta }\end{array}$ \\
\hline Passo 0 & INTENCIONADO 1 & INTENCIONADO (1) & 243 & 0 & 100 \\
& & NÃO INTENCIONADO (2) & 34 & 0 & 0 \\
Porcentagem Total & & & & 87,7 \\
\hline
\end{tabular}

Fonte: Elaboração própria.

ao menos 0,70. Após análise dos dados, encontrou-se a medida de 0,721, determinando, portanto, a consistência interna do instrumento como aceitável.

\subsection{REgRESSÃo LogístiCA}

Avaliou-se, inicialmente, o modelo apenas com intercepto, uma vez que esse modelo será uma referência de comparação para o modelo completo. A Tabela 2 informa que, quando a constante é inscrita no modelo, 243 visitantes de 277 observações se consideram intencionados a retornar ao evento, ou seja, 87,7\% dos entrevistados. Assim, caso fosse solicitada a indicação dos visitantes intencionados a retornar ao evento, 87,7\% seriam corretamente classificados ao acaso, considerando o modelo com apenas intercepto.

Tabela 2 - Tabela de Classificação$$
\text { Fonte: Elaboraçã própria. }
$$

\section{diante desse quesito.}$$
\text { Eonte: Elaboraç̃ própria. }
$$

\section{0,140}

As informações da Tabela 3 reafirmam que apenas a constante foi considerada no modelo, sendo exibido o resultado do teste de Wald. A hipótese nula de que o intercepto é zero foi rejeitada $(\mathrm{p}=0)$. Assim,

Logit $(Y=1)=-1,967$

$\mathrm{P}(\mathrm{Y}=1) /[1-\mathrm{P}(\mathrm{Y}=1)]=\mathrm{e}-1,967=$

Considerando o modelo apenas com intercepto, o

A consistência interna das questões descritas anteriormente (de 1 a 8 ) foi devidamente avaliada por meio da medida denominada Alpha de Cronbach, cuja premissa básica consiste em avaliar a confiabilidade interna do instrumento de coleta de dados (questionário). HAIR et al. (2007) recomendam que essa medida seja de impacto do intercepto sobre a chance é 0,140.

Tabela 3 - Variáveis da Equação

\begin{tabular}{|c|c|c|c|c|c|c|c|}
\hline & & B & S.E. & Wald & df & Sig. & $\operatorname{Exp}(B)$ \\
\hline $25 s 00$ & Constante & $-1,967$ & 0,183 & 115,367 & 1 & 0,000 & 0,14 \\
\hline
\end{tabular}

Fonte: Elaboração própria. 
A Tabela 4 exibe a lista de variáveis explicativas que não estão no modelo apenas com intercepto, mas que são candidatas à participação. Os escores eficientes de Rao, denominados tão somente escores, pelo SPSS, apresentam significância estatística para todas as variáveis da tabela, o que significa dizer que está sendo rejeitada a hipótese de que os coeficientes dessas variáveis sejam zero. O procedimento stepwise selecionará, inicialmente, aquela que apresenta o maior escore; no caso, a variável SACR3 será a primeira selecionada. Os escores são reavaliados e uma nova variável é novamente selecionada segundo o mesmo critério, a qual será, no caso, SACR2, e assim sucessivamente.

Tabela 4 - Variáveis não constantes na equação

\begin{tabular}{|c|c|c|c|c|}
\hline & Variáveis & Escore & $d f$ & Sig. \\
\hline \multirow[t]{8}{*}{ Passo 0 Variáveis } & IMG1 & 4,776 & 1 & 0,029 \\
\hline & SAT1 & 10,666 & 1 & 0,001 \\
\hline & SAT2 & 14,498 & 1 & 0,000 \\
\hline & SACR1 & 12,975 & 1 & 0,000 \\
\hline & SACR2 & 18,904 & 1 & 0,000 \\
\hline & IMG2 & 15,441 & 1 & 0,000 \\
\hline & SACR3 & 20,776 & 1 & 0,000 \\
\hline & SAT3 & 3,616 & 1 & 0,057 \\
\hline Estatísticas Globais & & 42,100 & 1 & 0,000 \\
\hline
\end{tabular}

Fonte: Elaboração própria.

A partir da Tabela 5, a consistência do modelo com intercepto e variáveis independentes será objeto de avaliação. Ela atesta a existência de significância estatística para todos os passos em que são inseridas variáveis independentes.

Tabela 5 - Teste Omnibus do Modelo de Coeficientes

\begin{tabular}{|ccccc|}
\hline & & Qui-quadrado & df & Sig. \\
\hline \multirow{3}{*}{ Passo 1 } & Passo & 17,647 & 1 & 0,000 \\
& Bloco & 17,647 & 1 & 0,000 \\
& Modelo & 17,647 & 1 & 0,000 \\
\hline \multirow{2}{*}{ Passo 2 } & Passo & 10,157 & 1 & 0,001 \\
& Bloco & 27,804 & 2 & 0,000 \\
& Modelo & 27,804 & 2 & 0,000 \\
\hline \multirow{2}{*}{ Passo 3 } & Passo & 5,397 & 1 & 0,020 \\
& Bloco & 33,201 & 3 & 0,000 \\
& Modelo & 33,201 & 3 & 0,000 \\
\hline
\end{tabular}

Fonte: Elaboração própria.
Na Tabela 6, verifica-se que enquanto novas variáveis são inseridas no modelo há uma melhora da bondade de ajustamento, já que a estatística -2LL exibe sucessivas reduções até o passo 3 . O modelo do passo 3 é o melhor, pois é aquele que exibe melhor ajustamento. À medida que o-2LL vai diminuindo, o erro de predição experimenta redução.

Simultaneamente, constata-se que as pseudoestatísticas de R2 aumentam de estágio para estágio, atingindo maior patamar na fase 3. O R2 de Cox e Snell situou-se no patamar de $11,3 \%$, ao passo que o R2 de Nagelkerke ficou em 21,5\%, ou seja, valores considerados relativamente baixos.

Tabela 6 - Sumário do Modelo

\begin{tabular}{|cccc|}
\hline Passo & -2 Log likelihood & Cox \& Snell R Square & Nagelkerke R Square \\
\hline 1 & 188,638 & 0,062 & 0,118 \\
2 & 178,481 & 0,096 & 0,182 \\
3 & 173,084 & 0,113 & 0,215 \\
\hline
\end{tabular}

Fonte: Elaboração própria.

Conforme a Tabela 7, dos 243 entrevistados que efetivamente se julgam intencionados a retornar ao evento, o modelo previu corretamente, 98,8\% (=240/243), falhando em relação à previsão de 1,2\% $(=3 / 243)$. De 34 entrevistados que se julgavam não intencionados a retornar ao evento, o modelo previu corretamente apenas 11,8\% (4 acertos entre 34 possíveis), classificando equivocadamente cerca de 88,2\% dos respondentes que não tinham efetivo julgamento de lealdade como se tivessem intenção de fazê-lo.

Em termos agregados, o modelo previu, com acerto, 88,1\% (4 julgamentos de não intenções de retorno acrescido de 240 acertos no julgamento de intenções, contra 277 possibilidades dos casos, ao passo que o percentual de acerto do modelo com apenas constante foi de $87,7 \%$ (213 possibilidades de intenções de retorno efetivas contra 243 possíveis). 
Tabela 7 - Tabela de Classificação

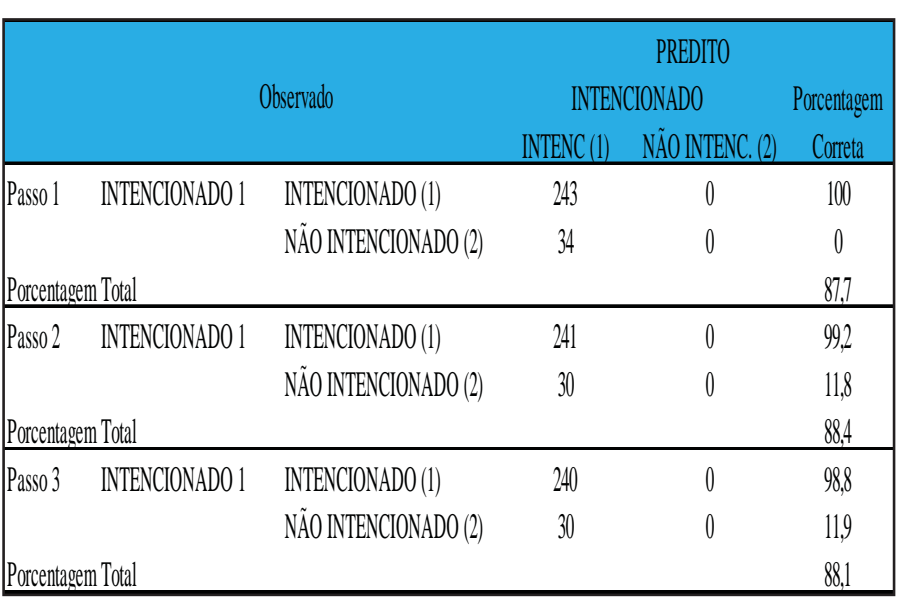

Fonte: Elaboração própria.

A equação de regressão logística pode ser expressa da seguinte forma:

\section{$\ln [\mathrm{p} /(1-\mathrm{p})]=3,083+(-0,418) * \mathrm{X} 1+(-0,420) * \mathrm{X} 2+$ $(-0,514) *$ X3.}

Para fins de amplificação, considere a seguinte notação:

\section{SACR3: X1 \\ IMG2: X2 \\ SACR2: X3}

Tem-se, então:

$$
\frac{p}{1-p}=e^{-3,083} \cdot e^{-0,418 \cdot X_{1}} \cdot e^{-0,420 \cdot X_{2}} \cdot e^{-0,514 \cdot X_{3}}
$$

Em termos simplificados, o efeito de cada variável sobre a chance de o indivíduo retornar ao evento deriva da antilogaritmização dos coeficientes de regressão logística (PAMPEL, 2000). Essa chance é ligeiramente influenciada pela variável SACR2 (horário do evento), cujo antilogaritmo $(\mathrm{e}-0,514=0,598)$ exerce maior impacto negativo sobre a chance e pela variável IMG2, cujo antilogaritmo $(\mathrm{e}-0,420=0,657)$ exerce o segundo maior impacto negativo.

A Tabela 8 mostra que três variáveis independentes são estatisticamente significativas na explicação das intenções de retorno do visitante à Costa Verde Negócios, quais sejam: SACR2, referente ao horário do evento;
IMG2, relacionada à imagem do evento e sua contribuição para a economia local; SACR3, referente à localização do evento. Os coeficientes de regressão logística das aludidas variáveis apresentam significância estatística, conforme indicado pelo teste de Wald.

O teste Wald verifica a hipótese nula de que o coeficiente seja igual a zero, o que significaria constatar a ineficiência da variável explicativa em predizer a variável dependente. Para rejeitar essa hipótese, a probabilidade deve ser inferior a 0,05. No passo 3, todos os coeficientes se revelaram importantes e possuidores de habilidade preditiva.

Tabela 8 - Variáveis da Equação

\begin{tabular}{|clcccccc|}
\hline & & B & S.E. & Wald & df & Sig. & Exp(B) \\
\hline \multirow{2}{*}{ Passo 1} & SACR3 & $-0,624$ & 0,147 & 18,046 & 1 & 0,000 & 0,536 \\
& Constante & 0,383 & 0,546 & 0,492 & 1 & 0,483 & 1,466 \\
\hline \multirow{4}{*}{ Passo 2} & SACR2 & $-0,539$ & 0,167 & 10,367 & 1 & 0,001 & 0,583 \\
& SACR3 & $-0,508$ & 0,152 & 11,152 & 1 & 0,001 & 0,601 \\
& Constante & 1,896 & 0,739 & 6,587 & 1 & 0,010 & 6,658 \\
\hline \multirow{4}{*}{ Passo 3 3} & SACR2 & $-0,514$ & 0,170 & 9,123 & 1 & 0,003 & 0,598 \\
& IMG2 & $-0,420$ & 0,176 & 5,689 & 1 & 0,017 & 0,657 \\
& SACR3 & $-0,418$ & 0,157 & 7,126 & 1 & 0,008 & 0,658 \\
& Constante & 3,083 & 0,914 & 11,366 & 1 & 0,001 & 21,015 \\
\hline
\end{tabular}

Fonte: Elaboração própria.

Com base nos dados das tabelas 7 e 8 , inferese que o modelo de regressão logística apresentou resultados razoáveis, podendo-se deduzir que, com um índice de acerto (em termos agregados) de $88,1 \%$, o modelo pode predizer que as variáveis SACR2, IMG2 e SACR3 influem diretamente na intenção de retorno ao evento por parte do visitante.

De acordo com o modelo empregado, a SACR3 é a variável que mais explica a intenção do visitante em retornar ao evento. Em outras palavras, uma mudança do local do evento (da praia do anil para outro espaço) diminuiria as chances de retorno em 0,658 vezes. A variável IMG2, que trata da imagem de contribuição do evento para a economia local sob as lentes do público visitante, explica parte da intenção de retorno. Em outras palavras, caso o público passasse a perceber o evento como uma atividade sem contribuição expressiva à economia local ocorreria uma chance de diminuição da 
intenção de retorno de 0,657 vezes.

Por fim, um dado um tanto quanto interessante diz respeito ao horário do evento, tratado sob a ótica do visitante por meio da variável SACR2. Embora seja a variável que menos explique a intenção de retorno ao evento, uma mudança do horário do evento poderia acarretar a chance de sua diminuição em 0,598 vezes.

Quadro 2 - Situação de Aceitação das Hipóteses Propostas

\begin{tabular}{|c|c|c|c|}
\hline \multicolumn{4}{|c|}{ Hipóteses } \\
\hline $\mathrm{H1}$ & $\begin{array}{l}\text { A opinião favorável em relação ao evento como um todo exerce influência } \\
\text { positiva sobre a intenção favorável de retorno à feira. }\end{array}$ & SAT1 & Não aceita \\
\hline H2 & $\begin{array}{l}\text { A opinião favorável em relação à organizaç̃o do evento exerce influência } \\
\text { positiva sobre a intenção favorável de retorno à feira. }\end{array}$ & SAT2 & Não aceita \\
\hline H3 & $\begin{array}{l}\text { A opinião favorável em relação aos expositores exerce influência positiva } \\
\text { sobre a intenção favorável de retorno à feira. }\end{array}$ & SAT3 & Não aceita \\
\hline H4 & $\begin{array}{l}\text { A opinião favorável em relação à infrraestruturua do evento exerce influência } \\
\text { positiva sobre a intenção favorável de retorno à feira. }\end{array}$ & SACR1 & Não aceita \\
\hline $\mathrm{H} 5$ & $\begin{array}{l}\text { A opinião favorável em relação à adequação do horário do evento exerce } \\
\text { inflluência positiva sobre a intenção favorável de retorno à feira. }\end{array}$ & SACR2 & Aceita \\
\hline $\mathrm{H} 6$ & $\begin{array}{l}\text { A opinião favorável em relação ao local de realização do evento exerce } \\
\text { influência positiva sobre a intenção favorável de retorno à feira. }\end{array}$ & SACR3 & Aceita \\
\hline H7 & $\begin{array}{l}\text { A opinião favorável em relação à reputação do evento exerce influência } \\
\text { positiva sobre a intenção favorável de retorno à feira. }\end{array}$ & IMG1 & Não aceita \\
\hline H8 & $\begin{array}{l}\text { A opinião favorável em relação à imagem do evento, como elemento } \\
\text { fomentador da economia local, exerce influência positiva sobre a intenção } \\
\text { favorável de retorno à feira. }\end{array}$ & IMG2 & Aceita \\
\hline
\end{tabular}

Fonte: Elaboração própria

\section{Considerações Finais}

O objetivo central deste trabalho foi identificar as variáveis preditoras da intenção de lealdade à VI Costa Verde Negócios, evento realizado na cidade de Angra dos Reis-RJ, litoral Sul Fluminense. Inicialmente, com base na literatura especializada e, por conseguinte, nos pressupostos teóricos, propuseram-se oito hipóteses relacionadas à predição das intenções de retorno, baseadas nos elementos: satisfação do visitante, imagem do evento e sacrifício percebido. Verificou-se que das oito hipóteses apenas três foram aceitas (H5, H6 e H8). Contrariando algumas premissas teóricas (MOWEN; MINOR, 2008; GRÖNROOS, 2004; HAWKINS; MOTHERSBAUGH; BEST; 2007; FREDERICO; ROBIC, 2006; CORRÊA; CAON, 2002; SHETH; MITTAL; NEWMAN, 2001), as hipóteses, neste contexto, que relacionavam a satisfação como uma variável preditora das intenções de retorno (H1, H2 e H3), não foram aceitas, provavelmente pelo fato de os elementos referentes à satisfação pesquisados não possuírem diferenciais determinantes para a opinião do público visitante. Como o evento possui entrada franca, supõe-se também que o nível de exigência do público tenha caído sobremaneira. Acredita-se, ainda, que o público angrense alimente baixas expectativas de bom atendimento, uma vez que ele está numa região onde se acredita que o comércio local presta um mau atendimento.

Dessa forma, a variável "satisfação” - com o evento de um modo geral, com a organização dele e com os expositores - não exerceu preponderância na predição das intenções de retorno. Chama-se a atenção para o fato de que, embora tais variáveis não tenham se configurado como preditoras, o público em geral as avaliou bem, ou seja, os visitantes se consideraram satisfeitos.

Já em relação à imagem, notou-se que a boa reputação do evento (H7) não se mostra suficiente para predizer a intenção de retorno do cliente. Por outro lado, essa imagem, como elemento fomentador da economia local (H8), não só é vista com bons olhos pelo público visitante como também apresenta moderado poder de predição da intenção de retorno. Tal constatação demonstra que a população local, apesar de se situar no interior, numa região um tanto quanto provinciana, apresenta senso de responsabilidade social aflorada, que se revela na aceitação de H8. A crença no evento como fator mobilizador da economia local funciona como uma alavanca motivacional à participação do público e sua adesão a ele.

Em pesquisa anterior, Abdalla (2008) já havia demonstrado que a variável SACR2, definida pelo sacrifício percebido pelo público ante o horário de funcionamento do evento, fora uma variável de elevada contestação. Fortalecendo tal constatação, verificouse que o horário de funcionamento do evento (H5) se revelou como uma hipótese aceita e, portanto, preditora das intenções de retorno a ele. Embora fosse a variável com menor poder explicativo, uma mudança do horário do evento poderia acarretar a chance de diminuição nas intenções de retorno em 0,598 vezes. Em outras palavras, a prerrogativa corrobora os pressupostos teóricos de Grönroos (2004) e Bolton (1998), ao creditar a maior parcela do valor percebido em uma relação à minimização do sacrifício do cliente, e não ao aumento dos benefícios. 
É interessante apontar que, embora a infraestrutura do evento (H4) não apresente poder de predição às intenções de retorno, verifica-se que a localização (H6) interfere diretamente na predição, demonstrando, mais uma vez, que a minimização do sacrifício, proposta por Grönroos (2004) e Bolton (1998), apresenta influência determinante nos resultados desta pesquisa.

Entre os pontos relevantes do presente trabalho, destaca-se a demonstração da importância da redução do sacrifício em transações relacionais, especialmente no contexto dos serviços voltados aos eventos. Comprovouse, por meio da aceitação de duas das três hipóteses relativas ao sacrifício percebido, que nesse tipo de negócio o sacrifício se apresenta como um importante preditor da intenção de retorno. Destaca-se também a significação da imagem do evento como uma atividade que, de alguma maneira, possa trazer benefícios à sociedade, e a relevância dada, pelo público consumidor, a esse fator. A constatação denota elevada consciência social do público.

Recomenda-se à organização do evento que, ao definir o briefing das próximas edições, leve em consideração os atributos de maior relevância e mais propensos ao estímulo das intenções de retorno do visitante. Neste caso, destacam-se: (i) a imagem do evento, de maneira socialmente responsável; (ii) a comodidade proporcionada pelo evento, por meio de um horário de funcionamento abrangente e uma localização centralizada e privilegiada.

Acredita-se que esta pesquisa tenha principalmente duas limitações: a primeira delas aponta para o fato de que, apesar da regressão logística binária possuir robustez em seus resultados, os valores encontrados foram modestos, não sendo recomendadas generalizações. A segunda, refere-se a uma restrição de ordem metodológica, ou seja, a adoção de uma amostra por conveniência, em que se assume a possibilidade de vieses que impedem sua generalização.

Como agenda de pesquisas, propõe-se a replicação do estudo em outras edições do evento, com a finalidade de refinar os resultados. Propõe-se, ainda, a aplicação da pesquisa em outros eventos similares, como por exemplo, a Festa Literária Internacional de Paraty (FLIP), com o intuito de verificar a consistência do trabalho e sua possibilidade de generalização, bem como a ampliação da compreensão da temática, à luz das pesquisas empíricas.

\section{REFERÊNCIAS}

ABDALLA, M. M. Relatório de Pesquisa de Mercado: 5a Costa Verde Negócios. 2008.

AMINE, A. Consumers' True Brand Loyalty: The Central Role of Commitment. Journal of Strategic Marketing, v. 6, n. 4, p. 305-319, 1998. <http://dx.doi. org/10.1080/096525498346577>

AZEVEDO, P. R. M. Modelos de Regressão Linear. Natal: Editora da UFRN, 1997.

BOLTON, R. N. A dynamic model of the customer's relationship with continuous service provider: the role of satisfaction. Marketing Science, v. 17, $\mathrm{n}^{\circ}$ 1, p. 45-65, 1998. <http://dx.doi.org/10.1287/mksc.17.1.45>

BRITTO, J.; FONTES, N. Estratégias para eventos: uma ótica do marketing e do turismo. São Paulo : Aleph, 2002

CHAPMAN JR, E. A. Why Am I Here? Sales \& Marketing Management, fev. 1993.

CHURCHILL Jr., G. A.; PETER, J. P. Marketing: criando valor para os clientes. São Paulo: Saraiva, 2005, $2^{\mathrm{a}}$ ed.

COMITÊ DE PROMOÇÃO DA ASSOCIAÇÃO BRASILEIRA DE ANUNCIANTES. Guia para Realização de Eventos. Disponível em: <http://www. portaldapropaganda.com/p1/repositorio_imagem/ Guia\%20de\%20Eventos.doc>. Acesso em 19 dez 2009.

CORRÊA, H. L; CAON. M. Gestão de Serviços: Lucratividade por Meio de Operações e de Satisfação dos Clientes. São Paulo: Atlas, 2002.

CROCCO, L.; GIOIA, R. M. Decisões de Marketing: Os 4 Ps. Coleção de Marketing vol.2. 1. ed. São Paulo: Saraiva, 2005.

DE TONI, D.; LARENTIS, F.; MATTI, A. A.; MILAN, 
G. S. A Imagem do Comércio Varejista e a Satisfação dos Consumidores: Um Estudo Exploratório Ambientado em uma Cidade da Serra Gaúcha. In: Encontro ANPAD, 32., 2008, Rio de Janeiro/RJ. Anais do XXXII EnANPAD. Rio de Janeiro: ANPAD, 2008. CD- ROOM.

DIAS FILHO, J. M.; CORRAR, L. J. Regressão Logística. In. CORRAR, L. J.; PAULO, E.; DIAS FILHO, J. M. D. (Org.) Análise Multivariada para os cursos de administração, ciências contábeis e economia. São Paulo: Atlas, 2007.

FREDERICO, E.; ROBIC, A. R. Estudo dos Fatores Determinantes da Satisfação do Consumidor com Vestuário Infantil. In: Encontro ANPAD, 30, 2006, Salvador/Bahia. Anais do XXX EnANPAD. Salvador: ANPAD, 2006. CD- ROOM.

HAIR, J. F.; ANDERSON, R. E.; TATHAM, R. L.; BLACK, W. C. Análise multivariada de dados. Porto Alegre: Bookman, 2005.

GIOIA, D. A.; SCHULTZ, M.; CORLEY, K. Organizational identity, image and adaptive instability. Academy of Management Review, v.25, n. 1, p. 63-81, Jan. 2000.

GOLDBERG, M.; LORIMER, E. J. Trade shows... their hidden value during these uncertain times. Skyline Exhibits. 2001. Disponível em: <http://www.skyline. ca/objectdsp/pdf/mkbrochures/whitepaper2000.pdf>. Acesso em 10 abr 2005.

GRÖNROOS, C. Marketing: gerenciamento e serviços. Rio de Janeiro: Elsevier, 2004.

HALL, R. The strategic analysis of intangible resources. Strategic Management Journal, v.13, n. 2, p.135-144, 1992. <http://dx.doi.org/10.1002/smj.4250130205>

HAWKINS, D. I.; MOTHERSBAUGH, D. L., BEST, R. J. Comportamento do Consumidor: Construindo a Estratégia de Marketing. 10. ed. Rio de Janeiro: Elsevier, 2007.
KHALIFA, A. S. Customer value: a review of recent literature and an integrative configuration. Management Decision, v. 42, $\mathrm{n}^{\circ}$ 5, p. 645-666, 2004. <http://dx.doi. org/10.1108/00251740410538497>

KONOPACKY, A. Turning trade show contact into sales. Chicago: Incomm Center for Sales training, 2005. Disponível em: <http://www.tradeshowresearch.com>. Acesso em 18 jan. 2010.

KOTLER, P. Administração de marketing: análise, planejamento, implementação e controle. trad. Ailton Bomfim Brandão. 5.ed. São Paulo: Atlas, 1998.

MAlhotra, N. K. Pesquisa de Marketing: uma orientação aplicada. 4ªed. Porto Alegre: Bookman, 2006.

MATIAS, M. Organização de eventos. Barueri: Manole, 2002.

MOWEN, J. C.; MINOR, M. S. Comportamento do consumidor. 6. Reimpr. São Paulo: Prentice Hall, 2008.

NASSARALLA, A. Feiras Setoriais em Arranjos Produtivos Locais como um Fenômeno de Marketing - O Caso FEVEST. Dissertação de Mestrado, 2006. MADE - Mestrado em Administração e Desenvolvimento Empresarial, Universidade Estácio de Sá, Rio de Janeiro, 2006, 249p.

OLIVEIRA, D. F. de. Identidade e Reputação no Setor Automotivo: Relacionando as formas de Imagem. In: Encontro ANPAD, 31, 2007, Rio de Janeiro/RJ. Anais do XXXI EnANPAD. Rio de Janeiro: ANPAD, 2007. CDROM.

PAMPEL, F.C. Logistic Regression: a primer. Thousand Oak: Sage, 2000.

PRIDE, W. M.; FERRELL O. C. Marketing: conceitos e estratégias. Rio de Janeiro: LTC, 2001.

RUST, R. T.; ZEITHAML, V. A.; LEMON, K. N. O Valor do Cliente: o modelo que está reformulando a estratégia corporativa. Porto Alegre: Bookman, 2001. 
SCHIFFMAN, L. G.; KANUK, L. L. Comportamento do Consumidor. 6. ed. Rio de Janeiro: LTC, 2000.

SHETH, J. N.; MITTAL, B. I; NEWMAN, B. I. Comportamento do Cliente: Indo Além do Comportamento do Consumidor. São Paulo: Atlas, 2001.

SCHULTZ, D. E.; ROBINSON, W. Sales promotion management. Lincolnwood: National Textbook, 1992.

STEVENS, R. P. Trade show and event marketing: plan, promoteandprofit.ThomsonHigherEducation:USA,2005.

STEVENSON, W. J. Estatística Aplicada à Administração. São Paulo: Harbra, 2002.

TANNER JR., J. F.; CHONKO, L. B. Trade show objectives, management, and staffing practices. Industrial Marketing Management, v. 24, p. 257-264, 1995. <http://dx.doi.org/10.1016/0019-8501(94)00082-8>

TERENCE,A.C.F.; FILHO, E.E.Abordagemquantitativa, qualitativa e a utilização da pesquisa-ação nos estudos organizacionais. In: ENCONTRO NACIONAL DE ENGENHARIA DE PRODUÇÃO, 26., 2006, Fortaleza. Anais do XXVI ENEGEP. Fortaleza, Ceará, 2006.

THURAU, T. H.; GWINER, K. P.; GREMLER, D. D. Understanding relationship marketing outcomes. Journal of Service Research, v.4, p. 230-247, Fev. 2002. <http://dx.doi.org/10.1177/1094670502004003006> 